\title{
Lugar-escola: territórios de relações e poderes
}

\author{
School place: territories of relations and powers
}

\author{
Danielle Gregole Colucci'
}

\section{RESUMO}

Relações de dominação permeiam experiências de sujeitos do mundo dos seus lugares à escala global. 0 objetivo deste texto é propor reflexões sobre o lugar-escola como território repleto de relações domesticadoras ou dialógicas, permeadas por exercícios de poder. No primeiro caso, trata-se de posicionamento político-pedagógico a favor da conformação social dos sujeitos ao mundo; no segundo, as intenções envolvem encontros e compartilhamentos desejosos de questionamentos e mudanças. Para tanto, se procura compreender a experiência comum da modernidade e suas hegemonias consolidadas. Entende-se que esse contexto contemporâneo tem envolvido a produção de conhecimentos, pedagogias e geografias.

Palavras-chave: Escola; Geografia; Hegemonias; Lugar; Relações de dominação

\section{ABSTRACT}

Domination relations permeate subjects' experiences from local to global scale. The purpose of this text is to propose a reflection on the school place as a territory of either domesticating or dialogical relations permeated by the exercise of power. Domesticating relations imply political-pedagogical positioning agreeing to the social conformity of the subjects to the world, while dialogical relations refer to encounters and sharing with the intention of questioning and changing. Therefore, it is necessary to understand the common experience of modernity and its consolidated hegemonies. It is understood that the contemporary scenario involves production of knowledge, pedagogical practices, and the geography.

Keywords: Domination relations; Hegemonies; School; Place; Geography

\section{INTRODUÇÃO: A EXPERIÊNCIA COMUM DA MODERNIDADE}

Quando, no interior destes escritos, se trata sobre as escolas é importante ressaltar que há aí uma generalização. O risco disso é que não se possa enquadrar a reflexão proposta em todo e qualquer contexto. Contudo, a justificativa para que tal generalização ocorra surge quando se acredita que existem semelhanças no fazer e no pensar do cotidiano escolar, independentemente de onde ele esteja. Apesar de cada escola possuir suas singularidades, algumas questões por elas vividas têm que 
ver com a macroestrutura que organiza e age sobre as instituições reguladas pelo aparato estatal e pelas corporações de mercado. Isso faz com que certas questões sejam fruto de problemáticas mais amplas, que estão além do lugar onde uma dada escola está situada, e que acabam as afetando coletivamente.

As relações hoje, entre os lugares e o mundo, se adensam, alargando contatos e tornando comuns algumas experiências existenciais (SANTOS, M., 2008, p.15). Por este motivo, acredita-se que, apesar de cada lugar possuir suas especificidades, e de receber de forma diversa o que lhe é externo, algumas questões podem e devem ser observadas conjuntamente à escala global e às relações nela travadas. Dessa forma, considera-se que as generalizações não são apenas legítimas, como também necessárias.

Assim, é interessante pensar as escolas para além de suas singularidades, a partir das interconexões que possuem com o mundo. O próprio processo de escolarização formal pode ser compreendido como parte da reorganização mundial que teve suas sementes lançadas ao solo por volta do século $\mathrm{XV}$, quando se começa a estabelecer o longo e inconcluso ciclo histórico denominado modernidade (CAMBI, 1999, p. 195). Não se pretende, aqui, fazer o estudo dos percursos históricos da modernidade e de seus processos, mas apenas localizar quando passaram a acontecer mudanças no contexto mundial e que possuem suas prevalências, inclusive no que tange as experiências escolares.

Portanto, pode-se dizer que as escolas são constituídas e constituintes de uma construção social - de cunho moderno-ocidental - consolidada a partir de uma forte lógica de regulação (SANTOS, B., 2006a). Nesse sentido, elas são, ao mesmo tempo, sêmen e fruto de uma sociedade que se organizou de maneira rígida e controlada. Assim, podem ser consideradas como lugares produzidos para cooperar com o estabelecimento de normas e com a conformação de comportamentos úteis aos interesses do mundo moderno.

Neste sentido, as escolas parecem ter papel fundamental no que diz respeito à formação educativa das populações que experienciaram a modernidade (e que, de certa forma, ainda a experienciam). Pode-se dizer que a experiência da modernidade 
é comum aos seus contemporâneos, visto que paulatinamente se difundiu, abarcando praticamente todos os lugares do mundo (BERMAN, 2007).

\section{RELAÇÕES DE DOMINAÇÃO: DOS SUJEITOS, DOS LUGARES, DO MUNDO}

No Brasil, país de primórdios coloniais e objeto, desde o início de sua formação, de profundas desigualdades sociais e relações de opressão, a tarefa domesticadora da educação formal (Cf. FREIRE, 2002) ainda prevalece. Isso porque se trata de um país constituído por uma sociedade intensamente estratificada e autoritária (CHAUI, 2007) voltada principalmente para os interesses de alguns grupamentos sociais hegemônicos: primeiro, de forças externas que estabelecem, desde a colônia até hoje, a divisão mundial do trabalho; depois, de uma minoria dirigente interna, atrelada aos interesses dos poderes globais. Ambos decidem os caminhos e descaminhos da grande maioria da população, posta apenas como objetos a serem usados como força de trabalho (RIBEIRO, 2006, p. 233).

Para tanto, criou-se todo um aparato institucional e ideológico que não só legitima a posição hegemônica destes grupamentos sociais, como mantém e assegura a posição de inferioridade sociocultural e econômica dos outros. Os critérios de estratificação de classe perpassam por variados símbolos de status que legitimam a posição que cada um ocupa na segmentação social. Assim, a forma como uma pessoa fala, veste, escreve, consome, locomove, onde ela mora, estuda, frequenta etc. acaba estabelecendo e acentuando as diferenças, o que, consequentemente, "[...] cria meios para a afirmação de distância e desigualdade sociais" (CALDEIRA, 2000, p. 259).

Obviamente, falar sobre a estratificação social é algo demasiadamente difícil. Isso porque o estabelecimento de uma determinada classe dominante, hegemônica e outra oprimida, subalterna, cria uma dualidade difícil de ser percebida, devido diversas subdivisões socioeconômicas estabelecidas ao longo da pirâmide social. Contudo, também não se pode deixar de negar que os setores da população possuem maior ou menor poder de decisão sobre as ações e direções a se tomar, dependendo 
de seu lugar no interior da pirâmide social. Os sujeitos hegemônicos detêm poder político e econômico suficiente para fazer valer suas vontades e privilégios.

Portanto, falar de divisão de classes sociais, apesar de ser algo complexo e relativo, é fundamental para que se possa compreender as relações de poder que se travam na atualidade. As dificuldades de se estabelecer como são, quantas são, onde se enquadram (dentre outras) as parcelas populacionais na pirâmide social somente reforça a ideia da existência da estratificação e, como o objetivo destes escritos não é o de desenvolver um estudo sobre o assunto, por agora, basta que se tenha em mente que a sociedade possui divisões estabelecidas a partir de diferenças e que acabam legitimando uma hierarquia desigual de poderes. Isso significa que cada sujeito exerce alguma forma de poder (Cf. FOUCAULT, 2009), com maior ou menor grau de decisão. Nem todos os poderes possuem a mesma intensidade, a mesma potência.

As diferenças entre os sujeitos do mundo são utilizadas como argumentos a favor do estabelecimento de relações de dominação, que vão muito além da simples estratificação social, pois constituem e legitimam as próprias relações de poder. Estas, embasadas pela lógica da opressão, se estabelecem nos mais variados setores sociais, inclusive entre um mesmo grupamento socioeconômico (CHAUI, 2011).

As relações de dominação podem ser percebidas, por exemplo, nas práticas patriarcais que se dão em uma família, onde o homem é quem impõem suas vontades sobre todos os outros membros do lar (no caso, esposa e filhos). O mesmo pode se dar com um professor em sala de aula, que se utiliza da autoridade profissional e geracional que the foi incumbida para fazer valer sobre os seus alunos, autoritariamente, seus mandos e desmandos. Assim como as diferenças étnicas acabam por criar a falsa ideia de superioridade de algumas etnias sobre outras.

Desta maneira, as relações de dominação estão entranhadas nas relações socioculturais como um todo. Elas se legitimam a partir de diferenças de classe, gênero, étnicas, socioeconômicas, culturais, físicas etc. Assim, transformam-se diferenças em desigualdades. Tais relações de opressão podem, inclusive, ocorrer no interior de determinado país, entre seus lugares; assim como entre estados (e 
corporações), que se dividem (não linearmente) entre setores dominantes, detentores de mais poder, e outros gradativamente menos atuantes enquanto setores decisórios.

Nesta sociedade mundial, estratificada, moldada sob a égide de relações de dominação, pode-se dizer que as escolas surgem como instituições privilegiadas de inculcamento do lugar social que cada sujeito ocupa (MÉSZÁROS, 2005). Nesse sentido, que possibilidades e limitações podem ser encontradas nos territórios[1] escolares?

\section{ESCOLAS E CONHECIMENTOS HEGEMÔNICOS}

Há algo que não se pode negligenciar em qualquer processo pedagógico: a sua intencionalidade política (FREIRE, 2002). Alguns questionamentos filosóficos são intrínsecos à educação intencional: para quê, a favor do quê e de quem? São perguntas inevitáveis, ou melhor, indicotomizáveis dela. Independente de se ter a clareza ou não da intencionalidade político-pedagógica de certo processo educativo, ela existe. Para toda prática-teoria pedagógica há um objetivo político: um para quê, um por quê.

Neste sentido, pergunta-se: para quê, a favor do quê e de quem têm sido as escolas historicamente? Desde os primórdios da escolarização formal, há algo latente: a educação dos grupos menos favorecidos economicamente - que é composta pela maior parcela da população — não é a mesma dos segmentos hegemônicos. Ao mesmo tempo, a distribuição social do trabalho também é bem distinta e, consequentemente, está intimamente relacionada com o tipo de educação que cada um deve (e pode) ter acesso.

Quando, nestes escritos, se fala sobre a escolarização formal, deve-se logo associa-la à atuação do estado enquanto seu provedor e regulador. Isso porque "... a escolarização, no mundo moderno, faz-se a partir dos agenciamentos de dar a ver e fortalecer as estruturas de poder estatais podendo, mesmo, ser considerada como um dos momentos de realização dos estados modernos" (FARIA FILHO, 2003, p. 145-146). 
Por outro lado, isso não significa que historicamente os estados tenham agido autonomamente. Ao contrário, as instituições formais de ensino no Brasil pareceram se preocupar com a formação de cidadãos ordeiros e bem dispostos ao trabalho, em prol do desenvolvimento de uma sociedade harmônica e sem preconceitos, crentes na unidade da nação, independente, indivisa, homogênea e forte. Cidadania esta pronta para atender passivamente às exigências das agências exteriores e das grandes corporações de mercado (COLUCCI, 2013).

Tais representações acabam encobrindo ideologicamente as desigualdades brasilianas e suas contradições, reproduzindo historicamente as relações de dominação e poder estabelecidas deste o período colonial. Ao estado — intimamente relacionado aos sujeitos hegemônicos e também constituído, em grande medida, por eles; a favor e em prol dos seus interesses (CHAUI, 2011) - jamais interessaria uma população capaz de questionar posições sociais.

A educação escolarizada no Brasil possui, ao longo de sua trajetória, uma função social conformadora bem estabelecida. A dita educação bancária denunciada por Freire (2002) ainda na década de 60 é levada a cabo até os dias de hoje. O que se ensina e o que se aprende não deve ultrapassar os interesses funcionais e laborais que cada período histórico exige de seus indivíduos, compreendidos como força de trabalho segmentada segundo as vontades dominantes. Isso desde as escolas de primeiras letras - que se detinham em ensinar a ler, a escrever e a contar (FARIA FILHO, 2003) - até as escolas contemporâneas, que focam seus esforços na formação de habilidades e competências, bem ao gosto do trabalhador moderno do mercado flexível.

Desta forma, para que tais bases estruturais se reproduzissem ao longo da história, foi primordial que se criassem maneiras de aceitação dos sujeitos de sua posição e papel sociais. Nesse sentido, a educação escolarizada funcionou (e ainda funciona) como inculcadora da posição estratigráfica atribuída a cada pessoa "[...] na hierarquia social, juntamente com suas expectativas 'adequadas' e as formas de conduta 'certas'[...]" (MÉSZÁROS, 2005, p. 44). Obviamente, as instituições escolares não foram as únicas com tal função. As mídias, as igrejas, dentre outras, também 
tiveram atuação decisiva nesse processo. Entretanto, abordá-las todas exigiria esforços para além dos intencionados neste texto.

As escolas se enquadram perfeitamente como instituições disciplinarizantes, para se utilizar um termo muito bem empregado e trabalhado por Foucault (2009). Segundo ele, o poder disciplinar realiza sua gênese através de instrumentos simples - como o olhar hierárquico, a sanção normalizadora e o exame (FOUCAULT, 2009) a fim de conseguir a conformação social segundo os interesses dominantes.

A noção hierárquica escolar pode ser explicitada ao longo de sua estruturação institucional. Dentro das salas de aula os estudantes são, não raramente, tratados como agentes passivos do processo de busca de conhecimentos dos professores, que estão subjugados à direção escolar, subalterna às decisões do estado.

O olhar hierárquico também pode ser percebido na organização do próprio currículo escolar. Há uma tentativa de empobrecimento dos saberes comuns, singulares, oriundos das experiências vivenciais. Em contrapartida, o conhecimento valorado é aquele gestado pelas e nas instituições de educação superior, subordinadas às estruturas rígidas da produção do conhecimento científico. Instituições estas onde, inclusive, ocorre a formação dos docentes. Isso significa dizer que os conhecimentos escolares que possuem maior valor estão associados à produção de conhecimentos hegemônicos.

O olhar científico inferioriza os outros saberes. A ciência moderna se apresenta ao mundo desde suas origens como o único conhecimento verdadeiro. E ela própria define soberanamente qual conhecimento tem ou não valor, é ou não correto, desqualificando o que não é fruto dela mesma (SANTOS, B. 2006). Assim, tornou-se paulatinamente, conhecimento hegemônico. Topo hierárquico.

O mesmo acontece com o uso da língua materna: por um lado denominada culta e por outro, inculta. A desvalorização das variações dialetais pelas escolas faz parte do seu cotidiano. O dialeto padrão é aquele considerado culto, correto, o único que domina o status de ser uma língua. Os outros dialetos — sejam variantes geográficas, culturais, geracionais, de classe, entre outras — são desvalorizados e invisibilizados. 
Assim, dependendo da forma como os alunos falam, se sugere sua inferioridade. Há o total desrespeito com suas maneiras de expressar o mundo, próprias de cada cultura, de cada contexto. Nesse caso, o olhar hierárquico do professor se faz na tentativa de arrancar (pela força) aquele jeito errado de falar e de expressar o mundo dos estudantes. Sua tarefa é mostrar-lhes sua inferioridade e ignorância, ensinando-os o modo correto de falar e de se comunicar. Daí o inevitável fracasso escolar (SOARES, 1986).

É interessante salientar que, apesar da tentativa de se transformar certo tipo de conhecimento hegemônico em conteúdo escolar - assim como de se estabelecer uma norma culta a ser seguida - isso não implica, necessariamente, que se deseja que a maioria da população domine-os. Pelo contrário, alguns poucos se sobressaem e conseguem dominar o capital cultural e linguístico. Aos outros, restam reprovações e evasões, além do brutal reconhecimento e aceitação do seu inferior lugar social.

Assim, pode-se dizer que a escola possui práticas referentes a violências simbólicas, que impõem a cultura e a linguagem dos grupamentos hegemônicos aos outros, ou seja, legitima e converte tal posição hierárquica dita superior em conhecimento escolar. Isso faz com que as relações de dominação se agravem, pois gera, primeiro, a legitimação de determinado grupo no topo da estratigrafia social e, por outro lado, cria o mercado dos bens simbólicos. As consequências disso são mais amplas e desastrosas do que se pode imaginar.

Neste sentido, o exame - mais um dos instrumentos disciplinares abordado por Foucault (2009) - se conjuga à hierarquização do próprio saber, julgando o que é cultura e o que não é. Através de avaliações, classificam-se os sujeitos que dominam ou não o cabedal de conhecimentos considerados como válidos e verdadeiros. O exame passa a ser ele mesmo um instrumento punitivo, não em sua forma negativa, mas a partir do merecimento daqueles que por ele conseguem se afirmar. Esta é a lógica da meritocracia, que classifica e hierarquiza as pessoas conforme seu merecimento.

Assim, há a redução do próprio conceito de cultura, que passa a soar como sendo um dado tipo específico de bens simbólicos dominados ou não por uma 
pessoa. A cultura, entretanto, está intimamente associada às práticas cotidianas de todos os grupos sociais. Cada um deles possui sua cultura, desenvolvida através da forma com que se relacionam com o mundo e suas maneiras de explicá-lo e compreendê-lo. A tentativa de hierarquização de uma cultura - considerada melhor, superior e única - sobre as outras é uma das formas de relação opressora típica da atualidade (FREIRE, 2002).

O que se pretende aqui é defender que não há uma cultura melhor ou pior do que a outra. As culturas são diferentes entre si, gestadas principalmente pelas histórias existenciais das pessoas e seus grupamentos sociais, e todas, sem exceção, possuem potencialidades e limitações. O enriquecimento das sociedades humanas está exatamente quando se mantém o diálogo entre as diversidades. Sendo assim, a tentativa de super valorar uma única cultura e difundi-la como verdade para todos auxilia o estabelecimento de desigualdades. A cultura deve ser vista "[...] como expressão do esforço criador do ser humano" (FREIRE, 2000, p. 97). Enquanto criadoras e, portanto, criativas, as culturas são carregadas de riquezas do fazer e do pensar das mulheres e homens que estão no e com o mundo.

Além disto, é preciso distinguir a cultura dos sujeitos simples, comuns, da cultura de massas, muitas vezes tidas como sinônimas, o que não são. As culturas singulares são constituídas de riqueza existencial, portanto, carregam consigo os legados históricos, as memórias, as heranças transmitidas de uma geração a outra. Já a cultura de massas está associada à difusão de valores através de veículos comunicacionais diversos - como o rádio e a televisão - e se apresentam como padrões homogêneos de se pensar e viver, muitas vezes a serviço dos interesses do mercado e dos poderes hegemônicos. Assim, ela não é criadora e, menos ainda, criativa. Tal massificação apenas promove o empobrecimento e o esvaziamento do saber historicamente gestado (SANTOS, M., 2001).

Por outro lado, a cultura de massas não pode ser confundida com a tentativa de transformar a cultura hegemônica acessível a todos os sujeitos. Apesar do objetivo de ambas ser o de supostamente pretender uma cultura única e global, apenas a cultura de massas é difundida para a maior parcela da população. A cultura 
hegemônica, apesar de se apresentar como universal, não se estende às massas. Ela é apenas utilizada como parâmetro classificatório da inferioridade daqueles que não a dominam.

Logicamente, a tentativa de fazer chegar uma unidade cultural nos lugares, não se processa de forma passiva ou igual. Cada lugar possui suas especificidades típicas, referenciadas em suas heranças culturais e linguísticas que, obviamente, são traduzidas na produção dos seus saberes. Quando se fala em modelo mundial, o que se está dizendo é que na tentativa de tornar algo único, as especificidades acabam ficando explícitas. Por mais que se tente criar um capital cultural universal, ou uma massificação, a forma como o novo ou o externo chega em cada lugar é diferente. Cada contexto é fruto do seu devir, e carrega consigo suas heranças historicamente gestadas (SANTOS, M., 2008). O movimento faz parte dos lugares.

Nas escolas isso não é diferente. Cada uma possui suas especificidades, e a possibilidade de receber o novo, o externo, de forma diversa. Mas o que se tem observado não é a resistência, e sim a recepção passiva pelas escolas da lógica do capital cultural unificado, transformando-as em lugares perversos de inaceitação das diferenças culturais. A hierarquia de pessoas, conhecimentos, comportamentos, etc. se faz presente em grande parte das instituições de educação formal. O exame classifica, organiza e coloca as pessoas nos seus devidos lugares sociais. E não se pode esquecer que estas diferentes formas de classificação e hierarquização são instrumentos utilizados nas instituições disciplinares, como Foucault (2009) alertou.

Além deles, a normalização também é instrumental disciplinador. Nas escolas ela está presente no controle dos tempos e dos espaços, assim como no dos comportamentos. A regra escolar geral deve ser obedecida a fim de que tudo corra dentro da sua norma-lidade. Os que não obedecem acabam sendo punidos, com a finalidade de que se corrijam (e isto se dá em todos os níveis hierárquicos). Aqueles obedientes acabam sendo ovacionados como exemplos a serem seguidos. Estes três instrumentos - hierarquia, normalização e exame - se entrecruzam e funcionam de forma concomitante. "O poder disciplinar é com efeito um poder que, em vez de se 
apropriar e de retirar, tem como função maior 'adestrar'; ou sem dúvida adestrar para retirar e se apropriar ainda mais e melhor" (FOUCAULT, 2009, p. 164).

As práticas e condutas da educação formal têm se mostrado capazes de disciplinar corpos e mentes, de torná-los dóceis. As condutas sociais vão adestrando para o trabalho, vão sendo aceitas e, inclusive, vão se transformando em algo desejável. Elas podem ser forjadas em cada sujeito que, aos poucos, é transformado em objeto, desumanizado. O trabalho, ação que permite a produção da vida, da existência, deixa de ser ação consciente sobre o espaço humanizado e passa a representar um ato opressor sobre mulheres e homens desumanizados. E o pior de tudo é que mecanismos como a escolarização acabam por naturalizar este processo desumanizante-desumanizador.

\section{GEOGRAFIAS E ESCOLAS: LIMITAÇÕES DOMESTICADORAS E POTENCIALIDADES TRANSGRESSORAS}

A geografia, desde seus primórdios, parece ter se preocupado em se legitimar como ciência moderna, ou seja, tomou para si os critérios que ela mesma estabeleceu para se fixar como conhecimento verdadeiro: único racional e capaz de leituras do mundo objetivas e válidas. Nesse sentido, a ciência geográfica — assim como os outros conhecimentos científicos - trouxe consigo, ao longo de sua trajetória, fragilidades que hoje parecem se salientar cada vez mais. A onipotência perseguida pelo cientificismo fez com que suas produções se esvaziassem de saberes ou linguagens que não fossem as suas próprias. Por outro lado, se cercou de objetos e métodos bem estabelecidos, ilhando, assim, suas disciplinas em limites epistemológicos praticamente instransponíveis (SANTOS, B., 2006).

A ciência geográfica também sofre com o legado das fragilidades internas, oriundas das fragmentações que foram se estabelecendo: geografias humanas, físicas; e suas consequentes outras subdivisões: geografias da população, climáticas, geomorfológicas etc. (LACOSTE, 2002). Tantas segmentações do mundo acabaram esvaziando as produções científicas (e geográficas) de tantos outros saberes 
extremamente ricos e capazes de leituras do mundo repletas de sabedoria, e não apenas de conhecimento (de ciência de algo). Obviamente, houve o empobrecimento científico e geográfico à medida que se desconsiderou - propositalmente e a favor dos grupos hegemônicos - a validade daquilo que era gestado e pensado fora dos âmbitos acadêmicos.

Há décadas o geógrafo Yves Lacoste (2002) desenvolveu um trabalho de crítica ao conhecimento geográfico e seus legados históricos. Propôs uma análise bastante interessante, que subdivide a geografia em duas práticas-teóricas distintas: uma, denominada "geografia do estado maior"; e a outra, "geografia dos professores". A primeira está centrada na produção de conhecimentos estratégicos, de cunho espacial, muito utilizados pelos estados (mais especificamente pelas forças armadas); e também pelas corporações capitalistas - diga-se, principalmente, pelas grandes empresas comerciais, financeiras e econômicas.

Já a dos professores é aquela praticada pelos profissionais do ensino de geografia nas escolas formais. Para o referido autor, ela carrega consigo o estigma de uma disciplina empobrecida, carregada de interesses de cunho político das camadas detentoras de mais poder na hierarquia social. Nesse sentido, ela se torna "[...] um discurso ideológico no qual uma das funções inconscientes, é a de mascarar a importância estratégica dos raciocínios centrados no espaço" (LACOSTE, 2002, p. 31). Trata-se de uma geografia de encobrimentos.

Apesar de há alguns anos - mais especificamente com o fim da ditadura militar no Brasil - a geografia ter passado por um intenso movimento de renovação, associado principalmente aos percursos da geografia crítica, tais transformações, tanto de métodos quanto teóricas, parecem não ter chegado às escolas formais (KAERCHER, 1999). Parecem, inclusive, em alguns casos, não ter chegado às próprias universidades que, não se pode deixar de lembrar, são as instituições formadoras docentes. As vertentes fenomenológicas também parecem ser relegadas a segundo plano. Assim, mesmo nas universidades, há a permanência dos modelos positivistas no fazer-pensar geográfico (HISSA, 2008). 
O mundo, na teoria e na prática geográfica escolar (herdadas das academias de ciências), é fragmentado em questões sociais, climáticas, morfológicas, pedológicas, ambientais etc., assim como a própria geografia surge ramificada em física, humana, econômica, da população, entre outras. Isso pode ser observado nas escolas formais e nos conteúdos de alguns livros didáticos, seguidos como manuais de instrução e guias curriculares (RESENDE, 1989). Desta maneira, a disciplina ainda é vista pelos alunos (e, quem sabe, até mesmo por seus professores) como um conhecimento menor (como no caso das ciências humanas e sociais em geral), muitas vezes inútil e enfadonho, para relembrar novamente a obra de Lacoste (2002).

Em resumo, a geografia escolar parece continuar fundada basicamente em seus referenciais tradicionais, esvaziada de complexidade e da tão proferida visão de totalidade do mundo. A disciplina não leva em conta a historicidade humana e nem o contexto dos estudantes. "Ao negar o espaço histórico do aluno (da geografia), ela marginaliza o próprio aluno como sujeito do processo do conhecimento e transformao em objeto deste processo" (RESENDE, 1989, p. 20). Retira também a possibilidade de fazer valer aqueles "saberes de experiência feitos" (FREIRE, 2000, p. 83), oriundos da vida de cada um, carregados de significação e sentido, capazes de explicar e compreender o mundo porque carregados de emoção, de curiosidade, de sensibilidade, de significações do viver.

Entretanto, pensando-se no papel exercido pela escolarização formal ao longo da história brasiliana, não é de se estranhar que a geografia, em seu interior, se preocupe mais em empobrecer e esvaziar de sentido as contradições dadas no país e as relações do ser humano com o mundo, do que em fazer com que sejam explicitadas e compreendidas e, quem sabe, até superadas. Ela apenas se insere no contexto da educação bancária, que se instaurou no país desde a fundação dos institutos de educação formal pelo estado e, inevitavelmente, acompanha sua lógica disciplinar e domesticadora (KAERCHER, 1999).

É óbvio que, no interior de todas estas críticas, não há como esquecer os problemas que atingem grande parte das escolas públicas no Brasil, relegadas ao descaso estatal e às péssimas condições físicas. Concomitante a elas, o corpo docente 
(inclusive no caso específico dos professores de geografia) suporta condições precárias de trabalho e carrega consigo, além disso, sua frágil formação acadêmica, a falta de incentivos profissionais, de suporte pedagógico e/ou estrutural dos mais variados, dentre outras infinitas carências.

Também a precariedade econômica da vida de alguns estudantes, que em casos extremos chega à condição de miserabilidade completa (RESENDE, 1989), é recebida pela escola trazendo consigo questões que muitas vezes ultrapassam sua capacidade de intervenção. Tudo isso, logicamente, prejudica quaisquer tentativas de modificação nas estruturas vigentes e acaba justificando, e talvez até legitimando, a reprodução das práticas pedagógicas bancárias.

Contudo, o reconhecimento das fragilidades e limitações, tanto da escola formal quanto da "geografia dos professores", não é algo que possa se ater apenas às críticas do que é potencialmente negativo. Denúncias exigem anúncios do que pode ser superado (FREIRE, 2000). As possibilidades existem e podem germinar, desde que se parta da estrutura em que se está. O novo pode surgir do que está dado, do existente.

Desta forma, aqui o lugar surge como um ponto central de reflexão, visto que o mundo está intimamente associado à forma como as pessoas vivem. Ele é, em si, uma abstração, porque é entendido pelas mulheres e homens a partir do lugar onde vivem, de seu contexto (HISSA; MELO, 2008). Mas, o que a escola formal e o ensino de geografia têm que ver com o lugar e com o mundo?

Não é de hoje que a geografia reconhece o lugar como uma de suas categorias analíticas. Por outro lado, o mundo também sempre foi, direta ou indiretamente, objeto de seus estudos. Mesmo porque, separar lugar e mundo, hoje, é algo, no mínimo, absurdo. "Ler o mundo é ler o espaço, é ler o lugar; é reconhecer no cotidiano os elementos sociais, culturais e naturais que formam o espaço [...]" (PEREZ, 1999, p. 36).

Desta forma, não é de se estranhar o quanto o lugar tem importância fundamental para a geografia. Entretanto, o lugar pode surgir nas escolas não apenas como categoria analítica, como algo abstrato a ser pensado, e sim como lugar em si, 
como contexto, como espaço feito de experiências existenciais, como lugar vivido a ser refletido: lugar-escola. Daí o lugar onde a escola está inserida (e a própria escola) passam a ser os objetos de estudo, que obviamente não são limitados a si mesmos, pois também são mundo.

Esta possibilidade de explicação e compreensão do lugar onde a comunidade escolar está inserida apresenta um potencial extremamente rico por três motivos: primeiro, porque parte do contexto dos educandos e educadores para que o seu processo de busca do conhecimento possa se dar de forma significativa; segundo, porque permite que as pessoas extrapolem o conhecimento do lugar a partir da sua própria existência, pois nos dias atuais os lugares se aproximam do mundo, apesar de cada um possuir suas singularidades; terceiro, reflexões críticas acerca do lugar onde se está inserido guardam potências transformadoras: o pensar e o agir de forma indissociável e que pode promover movimentos de mudança. "Saber pensar o espaço para nele se organizar, este deve ser o objetivo central de um ensino de Geografia comprometido com uma educação voltada para o exercício da liberdade e da emancipação" (PEREZ, 2001, p. 116).

Saber pensar, problematizar o lugar, o contexto geográfico dos educandos e educadores. Auxiliar o processo de aprendizagem de si mesmos e de seus espaços existenciais. Talvez esta seja uma possibilidade de geografia escolar, a fim de que estudantes e professores se organizem e intervenham a partir do seu próprio lugarescola. Assim sendo, seria possível romper com as estruturas disciplinares denunciadas por Foucault (2009), pelo lado de dentro?

\section{CONSIDERAÇÕES FINAIS: LUGAR-TERRITÓRIO, AS ESCOLAS E O PENSAR-AGIR}

As pessoas hoje se encontram fragmentadas socioespacialmente. Os valores hegemônicos contemporâneos pautam-se na competitividade exacerbada e nas relações de dominação, que eliminam grande parte das possibilidades de cooperação entre os sujeitos. O que se observa são os comportamentos individualistas e consumistas, estruturados sobre a égide de um único e grande interesse: a 
acumulação de riquezas e dinheiro (SANTOS, M., 2001). O maior desejo é o de consumir (a única ação perceptível porque legitimada pela estrutura vigente); por fim, resta apenas o imobilismo.

O uso da força acaba se tornando uma necessidade [...] indispensável para competir e fazer mais dinheiro; isso vem acompanhado pela desnecessidade de responsabilidade perante o outro, a coletividade próxima e a humanidade em geral (SANTOS, M., 2001, p. 58).

A lógica que reina é a do mercado e do consumo, o que importa é o ter cada vez mais (HISSA, 2008, p. 17).

O que se observa é um momento histórico em que a humanidade encontra-se distanciada de si mesma: homens e mulheres tratados e se tratando como objetos, como coisas. Assim caminham na contramão dos diálogos, da cooperação entre si e entre as palavras e as ideias. As pessoas vivem em meio a uma multidão solitária. Com o advento da metropolização, as convivências se tornam cada vez mais superficiais. Grandes aglomerações de gentes que não dialogam, que não se encontram de fato. Encontros feitos de acasos e descasos, uma multiplicidade de um só.

Algumas questões poderiam ser feitas: se as pessoas estão segregadas, desunidas, se a falta de cooperação é algo perceptível e se o individualismo é um valor amplamente difundido hoje, como tocar as pessoas com relação à importância dos diálogos entre as ideias? Que lugares poderiam agregar as pessoas e suas ideias? As escolas seriam lugares em potencial para que os diálogos ocorram? E nelas, a geografia poderia cooperar como integradora entre os saberes dos lugares, a ponto de auxiliar no compartilhamento e enriquecimento das leituras do mundo?

As dificuldades são inúmeras e igualmente os desafios. E é exatamente por isso que é importante discutir sobre as potencialidades e a necessidade do diálogo entre as ideias e onde (e como) o encontro destas ainda pode ser possível frente às dificuldades condicionantes da atual sociedade fragmentária. Talvez as escolas regulares de ensino fundamental e médio, apesar de todos os seus problemas, possam ser lugares privilegiados de encontro entre as pessoas, as culturas, os saberes; lugar de diversidade de linguagens e ideias, de diálogos possíveis. 
No caso mais especificamente da geografia, apesar das já conhecidas limitações disciplinares, esta pode ser capaz de promover junções entre diversos saberes e áreas do conhecimento (é preciso mudar a partir do contexto que está dado). Não se pode negar sua potencialidade.

[Isso porque] talvez a Geografia, desde o seu projeto original do século XIX, seja a única área do conhecimento que busca interpretar de modo unificado, em seu fundamento espacial, problemas ambientais de caráter físico-biológico e socioeconômico (HISSA, 2002, p. 277).

Não que esta visão seja sua exclusividade, pois outros campos do conhecimento coetâneo procuram desenvolvê-la, mas talvez esta característica histórica tenha legado à geografia uma maior liberdade na transformação do seu saber.

Assim, é importante debater sobre o que limita ou amplia as leituras do mundo e as potencialidades epistemológicas humanas e, mais especificamente, acerca das possibilidades da geografia enquanto disciplina, propondo que as escolas, talvez, sejam lugares em potencial de diálogos entre as ideias, numa sociedade carente de encontros e de relações mais humanas.

Propor as escolas como lugares de encontro não é algo difícil de visualizar. Hoje grande parte da população já foi ou é escolarizada. Em algum momento de suas vidas passou ou conviveu com uma escola. Seja nos grandes centros urbanos ou rurais, em bairros de periferia ou centrais. Hoje as escolas têm uma centralidade impressionante na vida das pessoas, mas nem sempre estão a seu serviço. É como se todo o seu potencial de lugar de encontro fosse desfeito pelas ações impensadas reproduzidas ao longo da história, feita de relações de opressão. Ao invés de encontros, praticam-se amontoados de gente.

Nos grandes centros urbanos viver as cidades parece ser algo complicado. As relações de dominação também se refletem nelas. O acesso à cidade, ao lazer, por exemplo, pode ser reduzido a uma parcela da população que tem condições de pagar por ele. Ao mesmo tempo, quando não se pode comprar o lazer, ele se potencializa nos lugares mais próximos de onde se vive a vida. Nesse sentido, as escolas podem ser consideradas como lugares acessíveis às pessoas. Nelas há certa infraestrutura - 
como quadras, cantinas, banheiros, salas - que nem sempre está ao alcance de grande parcela dos setores da população, mas que pode ser ocupada, inclusive, legitimamente, afinal integra instituições de domínio público.

Talvez, por isto as escolas possam ser consideradas lugares de encontro em potencial. Isso sem se falar nos encontros feitos diariamente por crianças e adolescentes em idade escolar. Em um mundo tão carente de lugares de trocas, de convívio social, as escolas surgem como lugares que precisam ser reapropriados significativamente por suas comunidades. Para tanto, é fundamental que se rompa com a reprodução das estruturas de dominação até hoje presentes em seu interior, abrindo caminho para outros tipos de relações, mais dialógicas e menos opressoras. Existem várias geografias escolares: aquelas domesticadoras, prontas para formar pessoas dóceis, pacíficas e ordeiras; e outras inconformadas, que através de relações dialógicas, estabelecidas em lugares de encontros, intencionam sujeitos reflexivos, críticos e transgressores.

Lugares onde o encontro prevalece, cercado de respeito pelas diferenças e por vontade de diálogos, acabam funcionando como eixos geradores de ideias. E as ideias são como esferas gigantes que não cessam de crescer. Quando compartilhadas dialogicamente se ampliam de maneira incessante. Ideias coletivas também podem gerar ações. Obviamente, o que é movente tem o potencial de mover - estruturas, funções, relações, espaços, histórias... Por isso as escolas reocupadas, reapropriadas e resignificadas pelas pessoas, se tornam lugar-território, repletas de potencialidades dialógicas; desejosas de transformações e inconformadas com autoritarismos.

\section{REFERÊNCIAS}

BERMAN, M. Tudo que é sólido desmancha no ar: a aventura da modernidade. Tradução de Carlos Felipe Moisés, Ana Maria L. Ioriatti. São Paulo: Companhia das Letras, 2007.

CALDEIRA, T.P.R. Cidade de muros: crime, segregação e cidadania em São Paulo. São Paulo: 34/Edusp, 2000.

CAMBI, F. A época moderna. In: __. História da Pedagogia. Tradução de Álvaro Lorencini. São Paulo: UNESP. Terceira parte, 1999. p. 195-374. 
CHAUI, M. Brasil: mito fundador e sociedade autoritária. São Paulo: Fundação Perseu Abramo, 2007.

CHAUI, M. Cultura e democracia: o discurso competente e outras falas. 13. ed. São Paulo: Cortez, 2011.

COLUCCI, D.G. Brasil dos brasis e outros ensaios. 2013. 113p. Dissertação (Mestrado em Geografia) - Universidade Federal de Minas Gerais, Belo Horizonte

FARIA FILHO, L.M. Instrução elementar no século XIX. In: LOPES, E.M.T, FARIA FILHO, L.M., VEIGA, C.G. 500 anos de educação no Brasil. 3. ed. Belo Horizonte: Autêntica, 2003. p. 135-150.

FOUCAULT, M. Microfísica do poder. Organização, tradução, introdução e revisão técnica de Roberto Machado. 36. ed. Rio de Janeiro: Graal, 2009.

FOUCAULT, M. Vigiar e punir: nascimento da prisão. Tradução de Raquel Ramalhete. 36. ed. Petrópolis: Vozes, 2009.

FREIRE, P.Pedagogia da indignação: cartas pedagógicas e outros escritos. São Paulo: Unesp, 2000.

FREIRE, P. Pedagogia do Oprimido. 34. ed. Rio de Janeiro: Paz e Terra, 2002.

HISSA, C.E.V., MELO, A. F. O lugar e a cidade; conceitos do mundo contemporâneo. In: HISSA, C. E. V. (Org.). Saberes ambientais: desafios para o conhecimento disciplinar. Belo Horizonte: Editora UFMG, 2008. p. 293-308.

HISSA, C.E.V.A mobilidade das fronteiras: inserções da Geografia na crise da modernidade. Belo Horizonte: UFMG, 2002.

HISSA, C.E.V. Fronteiras da transdisciplinaridade moderna. In:

(Org.). Saberes

Ambientais: desafios para o conhecimento disciplinar. Belo Horizonte: UFMG, 2008. p. 1531.

KAERCHER, N.A. Desafios e utopias no ensino de Geografia. 3. ed. Santa Cruz do Sul: EDUNISC, 1999.

LACOSTE, Y. Geografia: isso serve, em primeiro lugar, para fazer a guerra. Tradução de Maria Cecília França. 6. ed. São Paulo: Papirus, 2002.

MÉSZÁROS, I. A educação para além do capital. Tradução de Isa Tavares. São Paulo: Boitempo, 2005.

PEREZ, C.L.V. Ler o espaço para compreender o mundo: a função alfabetizadora da Geografia.Revista Presença Pedagógica. vol. 5, n. 28, p.29-39, jul./ago. 1999... 
PEREZ, C.L.V. Leituras do mundo/Leituras do espaço: um diálogo entre Paulo Freire e Milton Santos. In: GARCIA, R.L. (Org.). Novos olhares sobre a alfabetização. São Paulo: Cortez, 2001. p. 101-122.

RESENDE, M.S. A Geografia do aluno trabalhador: caminhos para uma prática de ensino. São Paulo: Loyola, 1989.

RIBEIRO, D. O povo brasileiro: a formação e o sentido do Brasil. São Paulo: Companhia das Letras, 2006.

SANTOS, B.S. Um discurso sobre as ciências. 4. ed. São Paulo: Cortez, 2006.

SANTOS, B.S. Para uma sociologia das ausências e uma sociologia das emergências. In: SANTOS, B.S. (Org.). Conhecimento prudente para uma vida decente: um discurso sobre as ciências revisitado. 2. ed. São Paulo: Cortez, 2006a. p. 777-821.

SANTOS, M. Por uma outra globalização: do pensamento único à consciência universal. 7.ed. Rio de Janeiro: Record, 2001.

SANTOS, M. Metamorfoses do espaço habitado: fundamentos teóricos e metodológicos da Geografia. 6. ed. São Paulo: EDUSP, 2008.

SOARES, M. Linguagem e escola: uma perspectiva social. 3. ed. São Paulo: Ática, 1986.

[1] "Quando se fala de território, neste estudo, pretende-se pensá-lo como um conceito amplo, híbrido. Um constructo histórico, compreendido a partir das diversas relações socioespaciais que, necessariamente, envolvem relações de poder. Nesse sentido, o território pode ser compreendido como valor ético, simbólico e vivencial dos sujeitos que nele habitam ou se relacionam. Que dele se utilizam e nele se organizam para produzir não somente sua existência, como, também, suas identidades, seus modos de vida, sentidos e significações. Uma acepção que além de necessariamente econômica e política, também é a expressão de um processo social, cultural" (COLUCCI, 2013, p. 12). Neste sentido, aqui, as categorias território e lugar se aproximam. 